\title{
INVESTIGATION OF ASPHALT TEXTURE ROUGHNESS ON FRICTION EVOLUTION FOR WHEELED VEHICLES
}

\author{
Laurencas Raslavičius, Algis Pakalnis, Artūras Keršys, \\ Ramūnas Skvireckas, Darius Juodvalkis \\ Dept of Transport Engineering, Kaunas University of Technology, Lithuania
}

Submitted 17 December 2015; resubmitted 20 February 2016; accepted 20 March 2016

\begin{abstract}
Novelty of the research lies in understanding the safety advantages of asphalt made using advanced pavement design process - compact asphalt pavement installation. Variation of tyre-road friction coefficient for this type of pavement design is new and little-studied phenomenon. The present study focuses on the research into tyre-pavement interaction on dry asphalt pavement surfaces to quantify the effect of microprofile on vehicle performance in establishing its braking conditions. The data on a number of different indications (vehicle speed, adhesion coefficients calculated on the basis of braking and friction forces, maximum adhesion coefficient $\mu_{\max }$ and its 'minimum' value $\mu_{100 \%}$ ) and measurement results generated using SRT- 4 device for investigation of two road stretches at intervals of $100 \mathrm{~m}$ are presented in this paper. The interdependence analysis of statistical variables $\mu_{\max }$ and $\mu_{100 \%}$ has also been presented to exhibit the use of the method. Following statistical parameters are taken into account during random value analysis in order to assess the homogeneity of data: average value, dispersion, standard deviation, confidence interval around a sample mean, and correlation function. Finally, we provide a map between the adhesion coefficient and the longitudinal slip rate for stable and unstable braking conditions of a vehicle.
\end{abstract}

Keywords: road condition monitoring; vehicle-pavement interaction; friction estimation; road surface roughness; wheel slip.

\section{Introduction}

Pavement surface characteristics change over time and they influence many aspects of tyre-road interaction (Vaiana et al. 2012; Praticò et al. 2010; Juga et al. 2013). It is well known that the vehicle's controllability decreases with speed (Rutka, Sapragonas 2011; Žuraulis et al. 2014; Sokolovskij et al. 2007; Pečeliūnas, Prentkovskis 2006). It means that under certain circumstances, a critical speed limit exists above which braking capability and controllability are lost and accidents may happen (Srirangam et al. 2014). Moving on an irregular road surface, a vehicle is usually subjected to random excitation (Sun 2002). If a vehicle moves down the same track repeatedly under the same movement conditions (such as vehicle stability, driving speed, etc.), the vibrations induced on the car body will be different in each case. This is caused by the road surface being a set of random irregularities making it impossible to repeat vehicle trajectory ideally. Patches and other surface irregularities in the surface indicate the asphalt is not durable and often result in roughness and waves (Viner et al. 2006). It was found that it is convenient to divide the range of texture wavelengths into three regions:

- Macroprofile - longitudinal road profile waves longer than $100 \mathrm{~m}$ and road bends. It is used in analysis of road vehicle driving dynamics for the assessment of forces in the surface plane acting at the road-wheel interface in a four-wheel vehicle (upward gradient, downward gradient, turn, etc.). Being dependent on the road track design and its method of construction, this is one of the most important road characteristics;

- Microprofile - longitudinal road profile waves having the length of 0.10 to $100 \mathrm{~m}$. Their actual length depends on the type of road surface analysed. Longitudinal road profile waves length could be referred to as the main cause of vehicle vibrations having a direct effect on a driving speed, fuel consumption, fatigue life of vehicle, etc. Wave length of microprofile may be 1 to 100 $\mathrm{m}$ for asphalt road, 0.5 to $100 \mathrm{~m}$ for gravel road, and 0.10 to $20 \mathrm{~m}$ for paved road; 
- Roughness. Although it does not cause any vibrations in a vehicle (road vibrations are mostly absorbed through the tyres), surface roughness has direct effect on the grip and wear of the road tyres, as well as is a sources of road noise.

Tyre-road interaction is not only a central problem to asphalt pavement design, but also has a profound impact on infrastructure management, vehicle suspension design, and transportation economy (Sun 2013). We found that methodologies for analysing vehicle-road interaction have been based on measurements of microprofile characteristics of automotive roads for a long time. Since the main function of the asphalt texture is to provide a safe and smooth ride for drivers, functional characteristics such as ride comfort and noise also are the target of optimization, especially for the wearing surface mixes (Flintsch et al. 2003); they should provide adequate friction and maintain a good level of ride quality. For the purpose of an investigation, the road is divided into several separate stretches of identical characteristics in order to better describe the road microprofile. One stretch may range from a few hundred meters to several kilometres. Usually, stretches of identical characteristics are selected based on statistical analysis of road microprofile (spectral density, correlation function, roughness dispersion, etc.). In practical analysis of road stretches having identical type of surface and level of wear, separate statistical criteria do not contradict the hypothesis stating that microprofile is a normalized stationary function. It has also been noticed that recurrence of stretches is rare (probably except for individual bumps, pits, etc.) on an actual road with non-uniform microprofile characteristics.

From the above literature survey, it is apparent that although there have been many in-situ, analytical and numerical studies performed to quantify the asphalt texture parameters on friction evolution for wheeled vehicles, still limited research was ensued to determine the variation zones of the adhesion coefficient that may be related to braking conditions of any vehicle. The present study focuses on the research into tyre-pavement interaction on dry asphalt pavement surfaces to quantify the effect of microprofile on vehicle performance in establishing both stable and unstable braking conditions. Novelty of the research lies in understanding the safety advantages of asphalt made using advanced pavement design process. The investigated road has been constructed in accordance with the requirements for Compact asphalt pavement installation instructions (LAKD 2014). Variation of tyre-road friction coefficient for this type of pavement design is new and little-studied phenomenon.

\section{Methodology}

\subsection{SRT-4 Dynamometer Trailer}

Wheel-road grip ratio has been measured by device SRT-4 manufactured at Road and Bridge Research Institute, Poland (http://eng.ibdim.edu.pl). As described by Pokorski et al. $(2009,2011,2015)$, it is able to investigate both road surface adhesion and automotive tyre anti-slip properties. Measuring equipment includes a single-wheeled dynamometer trailer, Ford Transit special purpose towing vehicle, and electronic measuring and recording devices. Measuring principles includes the measurement of road-tyre grip ratio on wet surface (layer of water between the wheel and the road surface merely acting as a lubricant), both when the wheel is rolled free and when the wheel rolls with longitudinal slip ratio varying between 0 and 1 or when the wheel is completely locked (Pokorski et al. 2011). The steady-state velocity of dynamometer trailer measurement wheel $v=$ $60 \mathrm{~km} / \mathrm{h}$. Braking is performed by means of compressed air that was supplied from compressor mounted in the vehicle. An automated water dispensing apparatus with a tank capacity of $300 \mathrm{~L}$ has been also mounted in Ford Transit van. The dynamometer trailer was equipped with computer-controlled brake system (two brake callipers with ventilated disk); permitted measuring wheel rim size - 13, 14 and 15 inches. Smooth measuring tyre with longitudinal grooves PIARC 165 R15 has been used in this case. Velocity is controlled by the operator who monitors the indications of velocity sensor (accelerometer) and gives commands to the driver.

\subsection{Measurement of Road Surface Roughness}

'Sand patch' - a wide spread method of contact measurement, has been used for macrotexture depth measurement. Measuring set includes:

- measurement containers $\left(25\right.$ and $\left.50 \mathrm{~cm}^{3}\right)$;

- flat disk of $100 \mathrm{~mm}$ diameter;

- measurement ruler;

- calibrated sand (sand particles range in diameter from $0.0625 \mathrm{~mm}$ (or $1 / 16 \mathrm{~mm}$ ) to $0.2 \mathrm{~mm}$ ).

During the testing process, 25 or $50 \mathrm{~cm}^{3}$ of calibrated sand are poured onto the surface of tested road stretch (Fig. 1). A heap of sand is then spread over the surface using the flat disk into a circular patch by light rubbing until the disk surface has reached the road surface macrotexture. lated:

The average height of microroughness $R_{v}$ is calcu-

$$
\begin{aligned}
& R_{v}=\frac{V}{A} ; \\
& A=\frac{\pi \cdot D_{\text {avr }}^{2}}{4},
\end{aligned}
$$

where: $V$ - poured sand volume; $A$ - sand patch area; $D_{a v r}$ - average measured diameter of the sand patch.

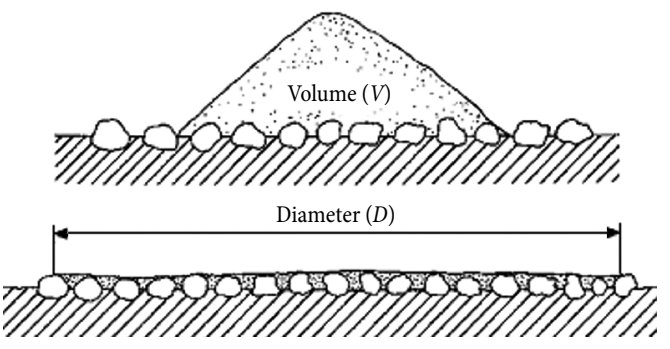

Fig. 1. The test method used to assess the surface texture depth 
Special scale is placed over the circular patch to measure the area. The measurement is repeated 5 times at the same experimental spot to find the average or arithmetic mean.

\subsection{Laser profilograph DYNATEST 5051 RSP}

Laser profilograph DYNATEST 5051 RSP (Fig. 2) has been used to measure the microprofile parameters of road surface. This is a versatile device that is applied to measure the longitudinal and transverse microprofile of the road surface. DYNATEST 5051 RSP is classified as a precision high-speed device for measurement of road surface characteristics. It incorporates a gyroscope; nine laser longitudinal and transverse road microprofile meters; measured distance sensor; two accelerometers eliminating self-oscillations of the measuring equipment; data acquisition software to process indications by laser measuring devices, gyroscope, accelerometers and measured distance sensor; PC for data storage and processing.

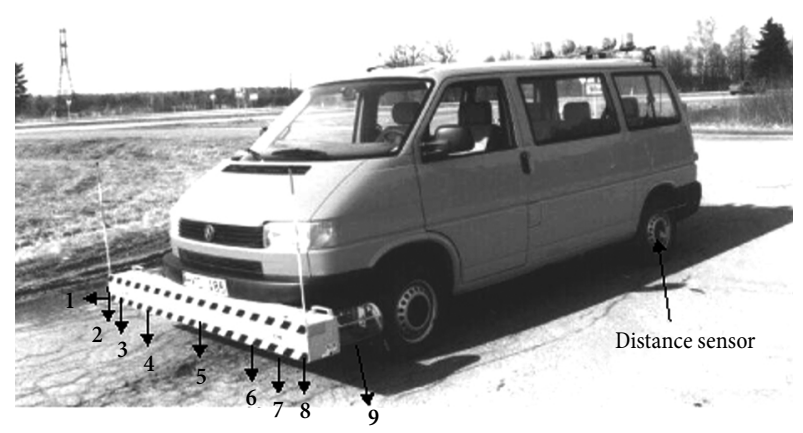

Fig. 2. Laser profilograph DYNATEST 5051 RSP

\section{Results and Discussion}

\subsection{Road Texture Evaluation}

Simulation of wheel-road interaction often requires evaluating the road surface, i.e. analysing the 'road-tyre' subsystem. In our specific case, asphalt texture roughness characterised by surface waves of 0.005 to $0.5 \mathrm{~m}$ length has been analysed. Theoretically, length of the analysed waves should be determined by the length of tyre contact area, which depends on geometrical parameters of the footprint.

In asphalt concrete survey and evaluation, measures of unevenness and skid resistance can be considered as random variables whose dispersion is to be attributed both to random errors of measurement and small heterogeneities of the surface (Cafiso, Di Graziano 2012). Therefore, it is appropriate to analyse data from surveys in order to identify homogeneous sections, for which it makes sense to define a mean value of the measure that also present significant differences compared to the averages of the sections before and after (Cafiso, Di Graziano 2012).

Pavement roughness data collection is usually seen as a set of random variables, meaning that statistical analysis methods are applicable to its analysis. Therefore, we tried to figure out the precision of adhesion coefficient's true values by calculating their reliability and dispersion. Following statistical parameters are calculated during random value analysis in order to assess the homogeneity of data (Table 1):

- average value;

- dispersion;

- standard deviation;

- confidence interval around a sample mean;

- correlation function.

This approach is in line with methodologies presented by (Dell'Acqua et al. 2013, Cafiso, Di Graziano 2012; Dreyer 2014; Misra, Das 2003). We repeated our experiments 5 times, all results reported are averaged over those 5 independent experiments. After the analysis of the obtained results it can be stated that the adhesion coefficient values remain relatively constant over the investigated stretches, with an exact confidence interval of 0.017 , which is about $2-4 \%$ (Table 1 ).

Table 1. Adhesion coefficient's measurements and statistical analysis of the results

\begin{tabular}{|c|c|c|c|c|c|c|c|c|c|c|}
\hline $\begin{array}{l}\text { Segments corresponding } \\
\text { to an investigated road }\end{array}$ & $\begin{array}{l}\text { Asphalt roughness } \\
{[\mathrm{mm}]}\end{array}$ & \multicolumn{5}{|c|}{$\begin{array}{l}\text { Individual test values } \\
\text { for adhesion coefficient }\end{array}$} & $\begin{array}{l}\text { Average } \\
\text { value }\end{array}$ & $\begin{array}{l}\text { Standard } \\
\text { deviation }\end{array}$ & Dispersion & $\begin{array}{c}\text { Confidence } \\
\text { interval }\end{array}$ \\
\hline \multicolumn{11}{|c|}{ Stretch X1 } \\
\hline 18 & 0.86 & 0.43 & 0.49 & 0.47 & 0.51 & 0.48 & 0.476 & 0.030 & 0.0009 & 0.026 \\
\hline 18.1 & 0.9 & 0.42 & 0.5 & 0.47 & 0.44 & 0.49 & 0.464 & 0.034 & 0.0011 & 0.029 \\
\hline 18.2 & 0.77 & 0.41 & 0.52 & 0.43 & 0.48 & 0.49 & 0.466 & 0.045 & 0.0020 & 0.039 \\
\hline 18.3 & 0.65 & 0.42 & 0.44 & 0.42 & 0.44 & 0.46 & 0.436 & 0.017 & 0.0003 & 0.015 \\
\hline 18.4 & 0.65 & 0.42 & 0.43 & 0.41 & 0.41 & 0.41 & 0.416 & 0.009 & 0.0001 & 0.008 \\
\hline \multicolumn{11}{|c|}{ Stretch X2 } \\
\hline 18 & 1 & 0.53 & 0.54 & 0.55 & 0.51 & 0.56 & 0.538 & 0.019 & 0.0004 & 0.017 \\
\hline 18.1 & 0.95 & 0.53 & 0.53 & 0.51 & 0.51 & 0.54 & 0.524 & 0.013 & 0.0002 & 0.012 \\
\hline 18.2 & 0.95 & 0.53 & 0.52 & 0.53 & 0.52 & 0.51 & 0.522 & 0.008 & 0.0001 & 0.007 \\
\hline 18.3 & 0.8 & 0.52 & 0.5 & 0.51 & 0.49 & 0.5 & 0.504 & 0.011 & 0.0001 & 0.010 \\
\hline 18.4 & 0.85 & 0.48 & 0.47 & 0.49 & 0.48 & 0.47 & 0.478 & 0.008 & 0.0001 & 0.007 \\
\hline \multicolumn{8}{|c|}{ Average value over interval: } & 0.0194 & 0.00053 & 0.017 \\
\hline
\end{tabular}


Further, three randomly selected one-meter-long road stretches with asphalt pavement have been chosen for the analysis. Further on, a relative ground level-line on a graph that runs horizontally (left right) through zero (Fig. 3) - has been established that allowed us to calculate the average height of irregularities $\bar{h}$ :

$$
\bar{h}=\lim _{L_{h} \rightarrow \infty} \frac{1}{L_{h}} \int_{0}^{L_{h}} h(x) d x,
$$

where: $h(x)$ - height of irregularities with reference to the ground level-line; $L_{h}$ - length of the measured stretch.

Dispersion of a dataset for each stretch analysed has been calculated by moving the ground level-line up at a height $\bar{h}$ :

$$
\sigma_{h}^{2}=\lim _{L_{h} \rightarrow \infty} \frac{1}{L_{h}} \int_{0}^{L_{h}} h_{0}^{2}(x) d x,
$$

where: $h_{0}(x)$ - height of irregularities with reference to the latest ground level-line.

Irregularities of asphalt texture whose spacing is greater than the roughness sampling length (hereinafter waviness) are described using the following correlation function:

$$
R_{h}^{*}\left(x_{s}\right)=\frac{1}{L_{h} \cdot \sigma_{h}^{2}} \int_{0}^{L_{h}} h_{0}(x) \cdot h_{0}\left(x+x_{s}\right) d x,
$$

where: $R_{h}^{*}\left(x_{s}\right)$ - normalized correlation function.

Correlation function provides information on the predominant wave length values for the described stretch, while its shape represents the predominant excitation frequency. As suggested by Fig. 4, waves of two lengths could be identified: longer waves, having the length of $0.25-0.4 \mathrm{~m}$, and shorter waves, having the length of about $0.04 \mathrm{~m}$.

Where correlation function has been noticed to imply presence of periodic waves, the computation and study of Fourier series (also known as harmonic analysis) has been used to describe the same profiles (Eq. (5)). Later on, dependence of amplitudes obtained after break up of an arbitrary periodic function into a set of simple terms and then recombined again in order to obtain the values of wave length has been analysed and presented in Fig. 5.

$$
h(x)=\frac{x_{0}}{2}+\sum_{i=1}^{\infty} a_{i} \cdot \cos (i \cdot \varpi \cdot x)+\sum_{i=1}^{\infty} b_{i} \cdot \cos (i \cdot \varpi \cdot x)
$$

Original applications developed at the university's department have been used for calculations of correlation function and harmonic analysis. The influence of stretch length on the predominant wave length values and amplitudes has been verified during the study. For this purpose, the analysed stretch has been shortened to $0.5 \mathrm{~m}$ length. The resulting dependence of amplitudes on the predominant wave length values for the stretches of different length is presented in Fig. 6. No significant influence of stretch length has been identified, but a shorter stretch could be considered as showing more evident predominant waves.

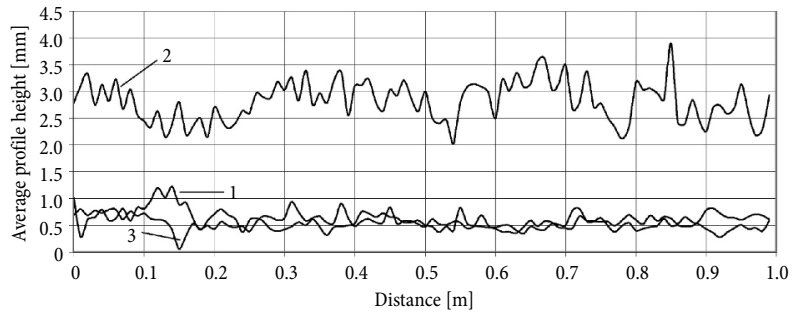

Fig. 3. Average height values of the asphalt pavement: $1,2,3$ - road stretches

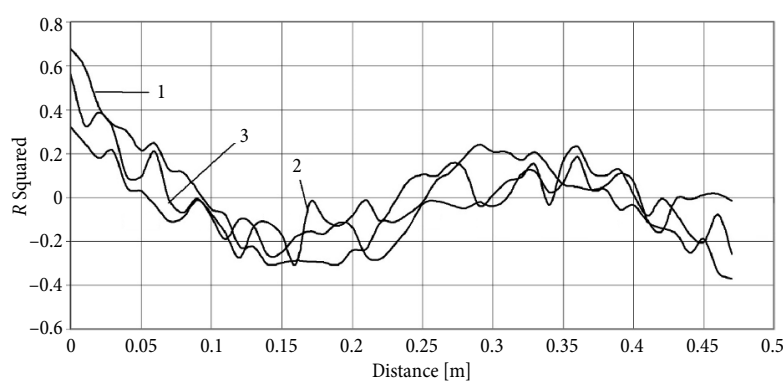

Fig. 4. The square of the Pearson correlation for the asphalt pavement: 1,2, 3 - road stretches

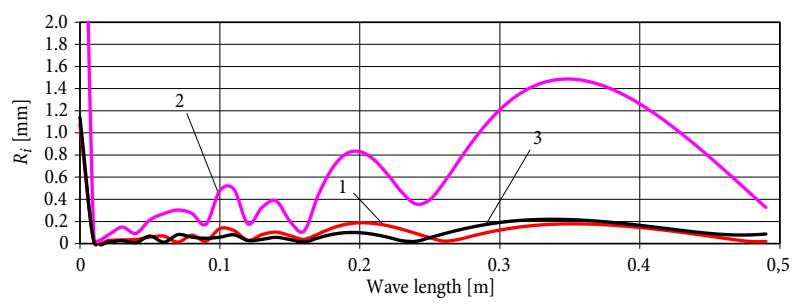

Fig. 5. Dependences of amplitudes on the predominant wave length values: 1, 2, 3 - road stretches

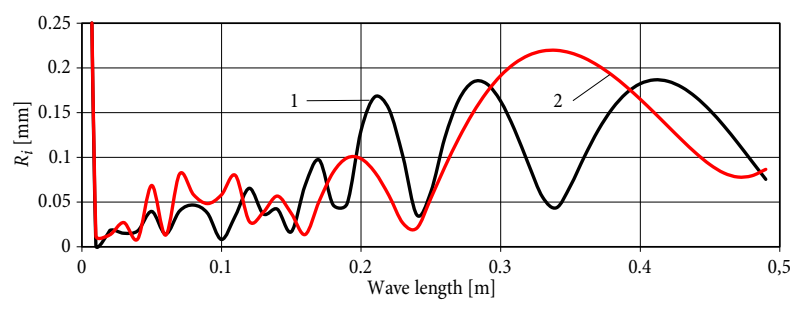

Fig. 6. Dependence of amplitudes on the predominant wave length values for the stretches of different length:

$$
1-1 \mathrm{~m} ; 2-0.5 \mathrm{~m}
$$

It is obvious that the period of waves is not constant, and wave length values are varying. As the waves of microirregularities are not periodic, roughness varieties could be claimed to be caused by the road coating technology. Shorter waves are determined by the size of bitumen-filler mastics and asphalt mixture fraction, while longer waves, which are associated with the shape of irregularity are determined by vehicle loads on the asphalt pavement. On the other hand, both harmonic analysis and correlation function analysis picked out a certain wave length group, that is associated with dynamic loads. These results are presented in Table 2.

The analysis results (Fig. 7) suggest that there are two types of waves within the car wheel to road contact 
Table 2. Results of stretches analysis (the length of the analysed stretch $-0.5 \mathrm{~m}$ )

\begin{tabular}{|c|c|c|c|c|c|}
\hline \multirow{2}{*}{$\begin{array}{l}\text { Stretch } \\
\text { No }\end{array}$} & \multirow{2}{*}{$\begin{array}{l}\text { Wave length dispersion } \\
\text { of the asphalt texture }\end{array}$} & \multicolumn{2}{|c|}{ Wave length values [mm] } & \multicolumn{2}{|c|}{ Amplitudes [mm] } \\
\hline & & $\begin{array}{l}\text { Under correlation } \\
\text { function }\end{array}$ & $\begin{array}{l}\text { Under harmonic } \\
\text { analysis }\end{array}$ & $\begin{array}{l}\text { Under correlation } \\
\text { function }\end{array}$ & $\begin{array}{c}\text { Under harmonic } \\
\text { analysis }\end{array}$ \\
\hline \multirow{2}{*}{1} & \multirow{2}{*}{0.117} & $3-6$ & 5 & $0.1-0.3$ & 0.05 \\
\hline & & $26-32$ & $20-30$ & $0.5-0.9$ & $0.1-0.3$ \\
\hline \multirow{2}{*}{2} & \multirow{2}{*}{0.532} & $3-6$ & $3-4$ & $0.1-0.3$ & $0.1-0.2$ \\
\hline & & $26-32$ & $25-30$ & $0.5-0.7$ & $0.7-0.8$ \\
\hline \multirow{2}{*}{3} & \multirow{2}{*}{0.117} & $3-8$ & 5 & $0.2-0.4$ & 0.05 \\
\hline & & $30-40$ & $20-30$ & $0.5-0.7$ & $0.1-0.3$ \\
\hline
\end{tabular}

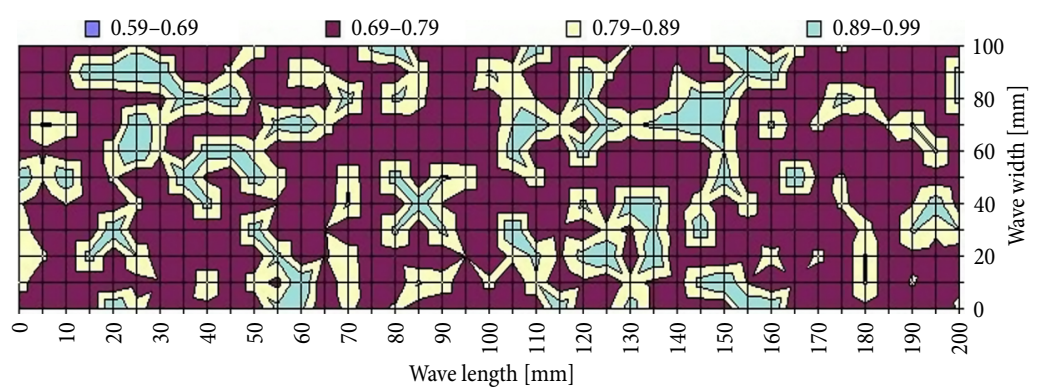

Fig. 7. View of road texture elements (intensity of colour denotes height above the median plane)

area: short waves, having the length of 3-6 $\mathrm{mm}(0.1-$ $0.3 \mathrm{~mm}$ amplitude), and long waves, having the length of 20-30 $\mathrm{mm}$ (0.5-0.8 mm amplitude).

\subsection{Estimation of Reliability of Measured Adhesion Coefficient' Values}

We found that the adhesion coefficient increases with the increase of surface roughness when the average height of microirregularities do not exceed $1 \mathrm{~mm}$ (Fig. 8). This dependence was unnoticeable for rough surfaces (at $R_{V}>1$ ). It can be explained by a more uniform contact area between a tyre and asphalt. The shape of microirregularities and the step-size between them are also very important parameters, meaning that the same roughness may sometimes exhibit different tribological phenomena.

The shape of irregularities in the pavement surface changes in the course of the road service life (Ueckermann et al. 2015; Start et al. 1998). In order to study the effects of uneven adhesion properties along the road surface, a two-lane highway road is selected as a typical example of the motorway that crosses Lithuania. Although in selected highway lanes' pavement ages were same, measured texture values for Lane\#1 and Lane\#2 were very different - the better adhesion has been exhibited on the second lane where traffic intensity is lower (Fig. 9). This could be explained by faster decrease of road surface roughness (Zhang et al. 2015).

Dependences of adhesive properties of the road on the actual dates of service of the asphalt pavement (including paving, crack filling, asphalt repairs) have been determined by analysing $1 \mathrm{~km}$ long stretch with renovated road surface (road coated on 12 August 2014). As shown in Fig. 10, the increase of the average coefficient values over time has been observed.

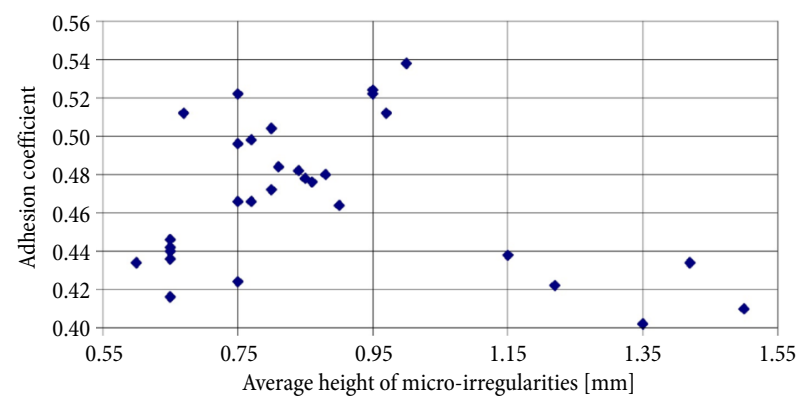

Fig. 8. Dependence of adhesion coefficient on road surface roughness

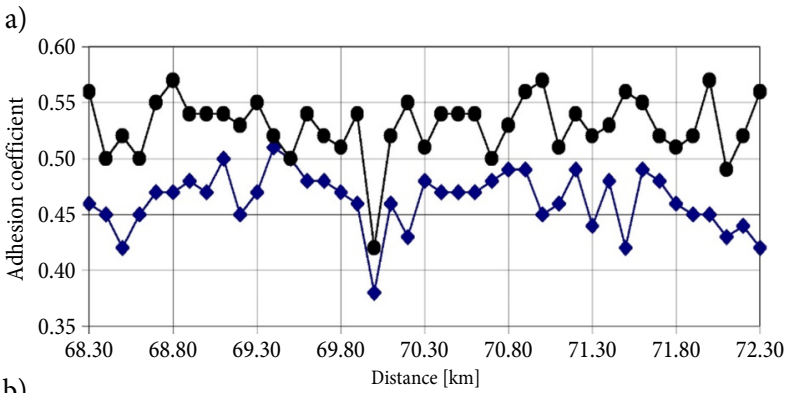

b)

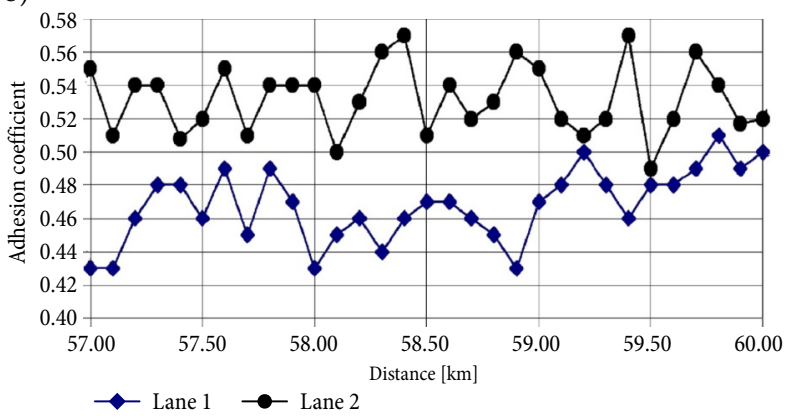

Fig. 9. Distribution of adhesive properties on investigated highway lanes: $\mathrm{a}$ - stretch X1, b - stretch X2 


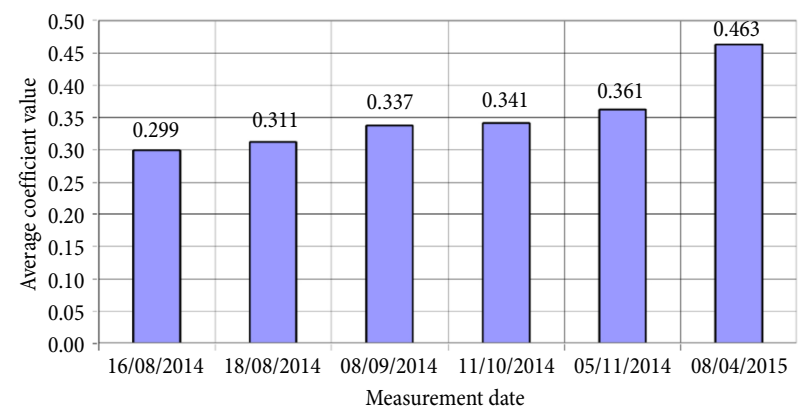

Fig. 10. Variation of average coefficient value for the experimental stretch over time

The effect of bitumen content on the road surface adds a factor to the road wear since this type of semi-solid hydrocarbon is gradually removed from the surface under traffic conditions - this results in better grip strength characteristics. As described by Labbate (2001), on a new asphalt surface, the microtexture can be masked by bitumen when the surface is initially laid and for a period afterwards until traffic and weather remove the excess bitumen to expose the microtexture. This phenomenon, often referred to as 'early life skid resistance', has been investigated in some depth in recent years (Labbate 2001; Do et al. 2009; Chen et al. 2011). After the initial period, the aggregates are gradually exposed and actual polishing of the aggregate particles begins, gradually reducing skid resistance to the equilibrium level (Labbate 2001).

\subsection{Analysis of Actual Relations Between Characteristic Values of Adhesion Coefficient}

To evaluate tyre-road interaction, two characteristic grip ratio values must be available: maximum (peak) friction resulting from partial slip, and minimum friction resulting from full blocking of the vehicle wheels. According to recommendations by the Permanent International Association of Road Congresses (PIARC, http://www.piarc. $o r g$ ), the ability of a vehicle tyre to grip the road initially should be analysed at $100 \%$ longitudinal slip. Averaged values of tyre-to-road adhesion coefficients are calculated using the following equations (Pokorski et al. 2011):

$$
\begin{gathered}
\mu_{M}=\frac{W}{F_{z}} ; \\
\mu_{T}=\frac{T}{F_{z}},
\end{gathered}
$$

where: $\mu_{M}$ - adhesion coefficient calculated on the basis of braking force $W ; \mu_{T}$ - coefficient calculated on the basis of friction force $T ; F_{z}$ - normal force.

As described by De Wit and Tsiotras (1999), the slip rate $s$ results from the reduction of the effective circumference of the tyre (consequence of the tread deformation due to the elasticity of the tyre rubber). Usually, the slip rate is defined in the interval $[0 ; 100]$. When $s=$ 0 there is no sliding (pure rolling), whereas $s=100 \%$ indicates full sliding. The most common tyre friction models used in the literature are those of slip/force maps
(De Wit, Tsiotras 1999). They are defined as one-to-one (memory-less) maps between the friction $F$, and the longitudinal slip rate $s$ (De Wit, Tsiotras 1999; Harned et al. 1969). The influence of various factors (structural, technological, operational, and atmospheric) on grip characteristics of road surfaces could be described broader for analysis of actual ratios between maximum adhesion coefficient $\mu_{\max }$ and its 'minimum' value $\mu_{100 \%}$. Fig. 11 presents the example of full adhesion characteristics $\mu=f(s)$ (slip/force map) with indicated threshold limit values for $\mu_{\max }$ and $\mu_{100 \%}$.

The entire adhesion coefficient's variation area is divided into two zones separated by the threshold value $\mu_{\max }$ and the respective relative slip $s_{m}$ line. Braking intensity indicated in the zone 1 is the most compatible with the brake pedal force that a person applies while braking on the brake pedal. The friction force in the tyre-road interface is the main mechanism for converting wheel angular acceleration (due to the motor torque) to forward acceleration (De Wit, Tsiotras 1999). Vehicle braking conditions are constant in this case (a human driver has full control over a car). Zone II is characterised by exceeded threshold value for $\mu_{\max }$ and unstable braking conditions thus leading to extremely reduced coefficient of road adhesion and often causing uncontrolled behaviour of the vehicle. In daily practice, during braking the value of road adhesion coefficient often falls within zone I with an exception for critical situations on the road - vehicle behaviour during operation at physical limits and in extreme situations. Both variation zones of the adhesion characteristics could be assessed rather accurately according to threshold values of $\mu_{\max }$ and $\mu_{100 \%}$ as well as according to longitudinal vehicle slip $s_{m}$, at which $\mu_{\max }$ value is achieved (dashed line, Fig. 11). Fig. 12 shows time dependencies of friction force $F$, braking torque $M$, normal force $F_{z}$ (loading measurement wheel of the dynamometer system), and rotation velocity $\omega_{k}$ of the measurement wheel.

The data on a number of different indications and measurement results generated using SRT-4 device for investigation of two road stretches (X1 and X2) at intervals of $100 \mathrm{~m}$ is presented in Table 3. Stretch X1 is characterized by high level of road adhesion maintained over the selected speed $v$, while stretch $\mathrm{X} 2$ is characterised by medium level.

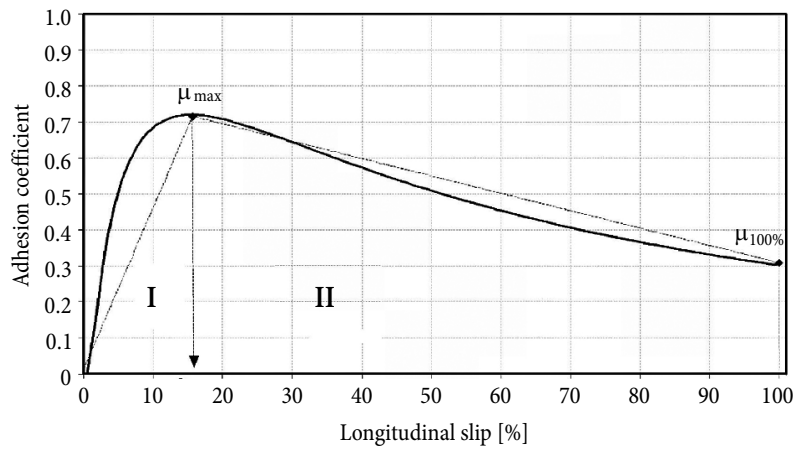

Fig. 11. Grip ratio $\mu=f(s)$ variation: zone I - stable braking conditions; zone II - unstable braking conditions 


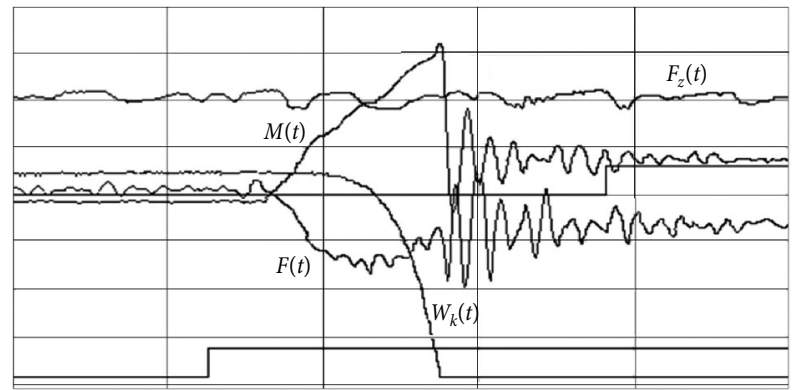

Fig. 12. Values $F(t), M(t), F_{z}(t)$ and $\omega_{k}(t)$ measured during measuring wheel braking (curves of dynamometer)

The graph ' $\mu_{\max } / \mu_{100 \%}$ ' of Table 3 suggests that the adhesion coefficient is not stable at certain measurement points, but varies within tight limits of tolerance. This is caused by relatively large number of identical surface characteristics of road stretches X1 and X2 that makes it impossible to ensure identical measurement conditions (constant measurement speed and surface structure). It should be noted that each road stretch has been characterised by different average grip level and different ratio between maximum adhesion coefficient and its 'minimum' value. Fig. 13 presents full adhesion characteristics (slip/force map) calculated using the data from Table 3.

The results have been verified by interdependence analysis of statistical variables $\mu_{\max }$ and $\mu_{100 \%}$. Fig. 14 reproduces the outcomes of statistical analysis.

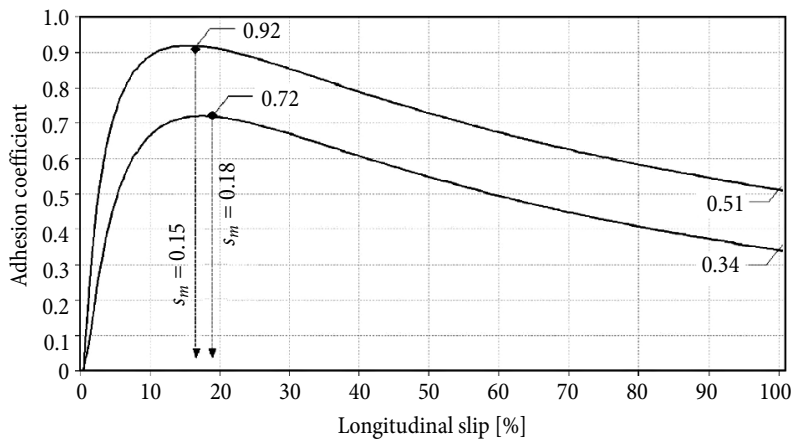

Fig. 13. Characteristics $\mu=f(s)$ drawn according to actual measurement values $\mu_{\max } / \mu_{100 \%}$ and $s_{m}$ for points '*' (stretches X1 and X2, see Table 3)
Table 3. Measurement results for road stretches X1 and X2

\begin{tabular}{|c|c|c|c|c|}
\hline$v$ & $\mu_{M}$ & $\mu_{T}$ & $\mu_{\max }$ & $\mu_{\max } / \mu_{100 \%}$ \\
\hline \multicolumn{5}{|c|}{ Stretch X1 } \\
\hline 59.6 & 0.48 & 0.49 & 0.89 & 1.85 \\
\hline 60.8 & 0.50 & 0.49 & 0.87 & 1.74 \\
\hline 60.2 & 0.49 & 0.48 & 0.93 & 1.89 \\
\hline 61.4 & 0.47 & 0.47 & 0.87 & 1.85 \\
\hline 61.7 & 0.48 & 0.47 & 0.90 & 1.87 \\
\hline 62.0 & 0.47 & 0.47 & 0.86 & 1.83 \\
\hline 60.5 & 0.49 & 0.50 & 0.90 & 1.84 \\
\hline 59.6 & 0.48 & 0.49 & 0.93 & 1.93 \\
\hline 62.0 & 0.50 & 0.49 & 0.91 & 1.82 \\
\hline 60.8 & 0.51 & 0.50 & 0.92 & $1.80^{*}$ \\
\hline $\begin{array}{l}\text { Average for } \\
\text { stretch X1 }\end{array}$ & 0.487 & 0.485 & 0.898 & 1.842 \\
\hline \multicolumn{5}{|c|}{ Stretch X2 } \\
\hline 60.2 & 0.33 & 0.32 & 0.75 & 2.27 \\
\hline 61.7 & 0.32 & 0.30 & 0.76 & 2.37 \\
\hline 57.9 & 0.35 & 0.34 & 0.75 & 2.14 \\
\hline 55.3 & 0.34 & 0.36 & 0.82 & 2.41 \\
\hline 61.1 & 0.31 & 0.29 & 0.70 & 2.26 \\
\hline 62.0 & 0.34 & 0.33 & 0.76 & 2.24 \\
\hline 61.1 & 0.34 & 0.32 & 0.72 & $2.12^{\star}$ \\
\hline 58.5 & 0.33 & 0.34 & 0.78 & 2.36 \\
\hline 56.7 & 0.34 & 0.34 & 0.74 & 2.18 \\
\hline 56.4 & 0.37 & 0.36 & 0.83 & 2.24 \\
\hline $\begin{array}{l}\text { Average for } \\
\text { stretch X2 }\end{array}$ & 0.337 & 0.330 & 0.761 & 2.259 \\
\hline
\end{tabular}

Note: ${ }^{*}$ fixed points for Fig. 13.

The obtained results have supported the hypothesis stating that the maximum value of $\mu_{\max }$ during partial tyre slip is almost twice as high as the 'minimum' value $\mu_{100 \%}$ (at full blocking of the vehicle wheels). The ratio of these two values depends highly on the characteristics of specific road surface and vehicle driving conditions.

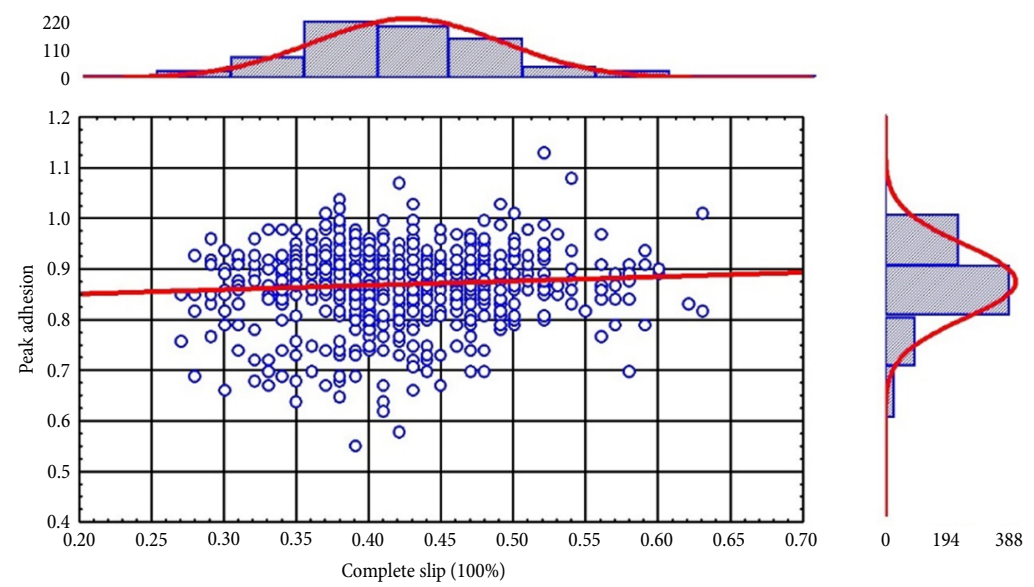

Fig. 14. Statistical distribution of interdependence between grip ratios $\mu_{\max } / \mu_{100 \%}$ 


\section{Conclusions}

Irregularities of asphalt pavement surface, from the small-scale unevenness on road surface to the largescale ones, all belong to spatial fluctuation of pavement surface at different scale. A new dynamic Mobile measurement system with successfully adopted surface-dependent tyre friction establishment devices for in-situ evaluation of asphalt texture has been applied for the research. Results of measured values of adhesion coefficient show its differentiation in dependence on the location of the measurement, traffic conditions, road surface exploitation time and many others. Hence, the concept and the methodology present in the article is not restricted to vehicle models and certain surface roughness. Following can be concluded from the research:

- Vehicle wheel-to-road adhesion coefficient has been found to increase with increasing roughness of road surface if average height of microirregularities does not exceed $1 \mathrm{~mm}\left(R_{v}=1\right)$. This dependence is unnoticeable for rough textures $\left(R_{v}>1\right)$.

- It has been determined that the maximum value of adhesion coefficient $\mu_{\max }$ during partial tyre slip is almost twice as high as its 'minimum' value $\mu_{100 \%}$ (at full blocking of the vehicle wheels).

- The analysis has determined that there are two types of waves within the zone of contact area between car wheel and road surface: short waves having the length of 3-6 $\mathrm{mm}(0.1-0.3 \mathrm{~mm}$ amplitude), and long waves having the length of 20-30 mm (0.5-0.8 mm amplitude).

- Microprofile characteristics have been identified for the selected highway lanes. Waves that distort the correlation function have been registered during both the statistical and harmonic analyses, even when conducted smooth surfaces. Nonetheless, the waves are scattered randomly and their lengths are not constant: amplitudes reach 1-2 $\mathrm{mm}$ for smooth surfaces and 5-20 mm for irregular surfaces.

\section{Funding}

The exploratory works were performed at Kaunas University of Technology (Lithuania) and funded as scheduled research activity.

\section{References}

Cafiso, S.; Di Graziano, A. 2012. Definition of homogenous sections in road pavement measurements, Procedia - Social and Behavioral Sciences 53: 1069-1079.

http://doi.org/10.1016/j.sbspro.2012.09.956

Chen, X.-H.; Steinauer, B.; Wang, D.-W. 2011. Evolution of aggregate surface texture due to tyre-polishing, Journal of Central South University of Technology 18(1): 259-265. http://doi.org/10.1007/s11771-011-0688-4

De Wit, C. C.; Tsiotras, P. 1999. Dynamic tire friction models for vehicle traction control, in Proceedings of the 38th IEEE Conference on Decision and Control, 7-10 December 1999, Phoenix, AZ, 4: 3746-3751.

http://doi.org/10.1109/CDC.1999.827937
Dell'Acqua, G.; Busiello, M.; Russo, F. 2013. Safety data analysis to evaluate highway alignment consistency, Transportation Research Record: Journal of the Transportation Research Board 2349: 121-128. http://doi.org/10.3141/2349-14

Do, M.-T.; Tang, Z.; Kane, M.; De Larrard, F. 2009. Evolution of road-surface skid-resistance and texture due to polishing, Wear 266(5-6): 574-577.

http://doi.org/10.1016/j.wear.2008.04.060

Dreyer, C. M. W. 2014. Evaluation of the Effect of Deteriorating Riding Quality on Bus-Pavement Interaction: a Dissertation Submitted in Partial Fulfilment of the Requirements for the Degree of Master of Engineering (Transportation Engineering). University of Pretoria. 148 p. Available from Internet: http://repository.up.ac.za/handle/2263/40331

Flintsch, G.; De León, E.; McGhee, K.; Al-Qadi, I. 2003. Pavement surface macrotexture measurement and applications, Transportation Research Record: Journal of the Transportation Research Board 1860: 168-177. http://doi.org/10.3141/1860-19

Harned, J.; Johnston, L.; Scharpf, G. 1969. Measurement of tire brake force characteristics as related to wheel slip (antilock) control system design, SAE Technical Paper 690214: 1-17. http://doi.org/10.4271/690214

Juga, I.; Nurmi, P.; Hippi, M. 2013. Statistical modelling of wintertime road surface friction, Meteorological Applications 20(3): 318-329. http://doi.org/10.1002/met.1285

Labbate, A. 2001. A Classification of Asphalt Surfacing Textures Based on 3D Imagery: MSc Thesis. University of Bologna. 152 p. Available from Internet: http://amslaurea.unibo. it/3967

LAKD. 2014. Kompaktiško asfalto dangu įrengimo metodiniai nurodymai MN KAD 14. Identifikacinis kodas 2014-02839. Lietuvos automobilių kelių direkcija (LAKD). (in Lithuanian).

Misra, R.; Das, A. 2003. Identification of homogeneous sections from road data, International Journal of Pavement Engineering 4(4): 229-233. http://doi.org/10.1080/10298430410001672237

Pečeliūnas, R.; Prentkovskis, O. 2006. Influence of shock-absorber parameters on vehicle vibrations during braking, Solid State Phenomena 113: 235-240.

http://doi.org/10.4028/www.scientific.net/SSP.113.235

Pokorski, J.; Reński, A.; Sar, H. 2015. System for investigation of friction properties of the road surface, The Baltic Journal of Road and Bridge Engineering 10(2): 126-131.

http://doi.org/10.3846/bjrbe.2015.16

Pokorski, J.; Reński, A.; Sar, H. 2011. Measurement system for investigation of tyre-road friction, in Proceedings of the International Scientific Conference Modern Safety Technologies in Transportation 2011, 20-22 September 2011, Zlata Idka, Slovakia, 331-337.

Pokorski, J.; Reński, A.; Sar, H. 2009. SRT-4 - Nowa generacja zestawu pomiarowego do badania przyczepności nawierzchni drogowych i opon samochodowych, Zeszyty Naukowe Instytutu Pojazdów - Proceedings of the Institute of Vehicles (2): 17-28. (in Polish).

Praticò, F. G.; Ammendola, R.; Moro, A. 2010. Factors affecting the environmental impact of pavement wear, Transportation Research Part D: Transport and Environment 15(3): 127-133. http://doi.org/10.1016/j.trd.2009.12.002

Rutka, A.; Sapragonas, J. 2011. The role of a tire in vehicle and road interaction, Transport 17(2): 39-45. 
Sokolovskij, E.; Prentkovskis, O.; Pečeliūnas, R.; KinderytėPoškienè, J. 2007. Investigation of automobile wheel impact on the road border, The Baltic Journal of Road and Bridge Engineering 2(3): 119-123.

Srirangam, S.; Anupam, K.; Scarpas, A.; Kasbergen, C.; Kane, M. 2014. Safety aspects of wet asphalt pavement surfaces through field and numerical modeling investigations, Transportation Research Record: Journal of the Transportation Research Board 2446: 37-51. http://doi.org/10.3141/2446-05

Start, M.; Kim, J.; Berg, W. 1998. Potential safety cost-effectiveness of treating rutted pavements, Transportation Research Record: Journal of the Transportation Research Board 1629: 208-213. http://doi.org/10.3141/1629-23

Sun, L. 2013. An overview of a unified theory of dynamics of vehicle-pavement interaction under moving and stochastic load, Journal of Modern Transportation 21(3): 135-162. http://doi.org/10.1007/s40534-013-0017-8

Sun, L. 2002. Optimum design of "road-friendly" vehicle suspension systems subjected to rough pavement surfaces, Applied Mathematical Modelling 26(5): 635-652. http://doi.org/10.1016/S0307-904X(01)00079-8

Ueckermann, A.; Wang, D.; Oeser, M.; Steinauer, B. 2015. Calculation of skid resistance from texture measurements, Journal of Traffic and Transportation Engineering (English Edition) 2(1): 3-16. http://doi.org/10.1016/j.jtte.2015.01.001

Vaiana, R.; Capiluppi, G. F.; Gallelli, V.; Iuele, T.; Minani, V. 2012. Pavement surface performances evolution: an experimental application, Procedia - Social and Behavioral Sciences 53: 1149-1160. http://doi.org/10.1016/j.sbspro.2012.09.964

Viner, H.; Abbott, P.; Dunford, A.; Dhillon, N.; Parsley, L.; Read, C. 2006. Surface Texture Measurement on Local Roads. Published Project Report PPR148. Transport Research Laboratory, UK. 89 p. Available from Internet: http://www.trl.co.uk/reports-publications/trl-reports/ report $/$ ?reportid $=5975$

Zhang, M.; Hua, G.; Zhang, C.; Ogle, J. 2015. Research on the horizontal curve's radius under coupling effects of uneven adhesion coefficient and crosswind, Journal of Traffic and Transportation Engineering (English Edition) 2(5): 346-352. http://doi.org/10.1016/j.jtte.2015.08.006

Žuraulis, V.; Levulyte, L.; Sokolovskij, E. 2014. The impact of road roughness on the duration of contact between a vehicle wheel and road surface, Transport 29(4): 431-439. http://doi.org/10.3846/16484142.2014.984330 